\title{
Effect of pre-transplant anaemia on perioperative cardiovascular morbidity and graft function in renal transplant patients
}

\author{
Ihab Abdel-Rahim Mohamed Ahmed, ${ }^{1,2}$, Walaa M. El-Jack ${ }^{1}$, Quratulain Shaikh ${ }^{3}$, Nada Mohammed Al Bawardi ${ }^{3}$, Nazik Khalifa Eldaif ${ }^{1}$, \\ Eltayeb Abdelrahman Musa ${ }^{1}$ and Mohamed Elhazif Elsharif ${ }^{1,4}$ \\ ${ }^{1}$ Renal Transplant Unit, Sharg El-Neel Hospital, Khartoum; Sudan \\ ${ }^{2}$ Department of Surgery. King Abdullah Ibn Abdulaziz University Hospital; Princess Nourah Bint Abdulrahman University, Riyadh, Kingdom of Saudi Arabia \\ ${ }^{3}$ Health Sciences Research Centre, Princess Nourah Bint Abdulrahman University, Riyadh, Kingdom of Saudi Arabia \\ ${ }^{4}$ Mafraaq Hospital, Abu-Dhabi, United Arab Emirates
}

\begin{abstract}
Introduction: Anaemia is a known complication of end stage renal disease (ESRD). The Kidney Disease: Improving Global Outcome (KDIGO) guidelines recommend that haemoglobin $(\mathrm{Hb})$ level in patients with ESRD should be maintained at $11-11.5 \mathrm{~g} / \mathrm{dl}$. However, it is difficult to achieve these figures in under resourced countries with limited setup where patients with ESRD frequently run low haemoglobin concentrations.

The aims of this study were to review the Hb levels and prevalence of anaemia in ESRD patients undergoing kidney transplantation in a transplant centre in Sudan and to explore the correlation of pre-operative anaemia with post-operative adverse cardiovascular events, delayed graft function (DGF), and frequency of blood transfusion.

Methods: Records of all patients who underwent kidney transplantation during the period Jan 2012 to Dec 2012 , were retrospectively reviewed. The variables analysed were pre-operative $\mathrm{Hb}$, frequency of perioperative blood transfusion, cardiovascular events during the perioperative period and frequency of DGF.

Results: Forty two patients were included in this study. The mean pre-operative Hb level was $10.26 \mathrm{~g} / \mathrm{dl}$ (SD: 2.05). Twenty six patients (62\%) had moderate or severe anaemia, as defined by the World Health Organisation, at the time of transplantation. None of the patients developed cardiovascular events during the perioperative period. There was no statistically significant association between pre-operative anaemia and DGF and frequency of blood transfusion.

Conclusion: Offering renal transplant to anaemic ESRD patients was not associated with adverse cardiovascular events. The frequency of DGF in anaemic patients was equivalent to those with normal $\mathrm{Hb}$.
\end{abstract}

\section{Introduction}

In 1836 Bright noted the association between anemia and chronic kidney disease [1]. Since then anaemia has become a well-recognised phenomenon in patients with end stage renal disease (ESRD) [2-4]. Both the Kidney Disease: Improving Global Outcome (KDIGO) and Kidney Disease Outcomes Quality Initiative (KDOQI) guidelines for haemodialysis patients recommend a target haemoglobin $(\mathrm{Hb})$ level of 11-11.5 g/dl [5]. Patients with lower Hb should be considered for erythropoiesis-stimulating agents (ESAs) and iron therapy [6]. In under resourced countries, however, such treatment modalities are not always feasible as these treatments may be limited due to financial constraints or availability [7]. In some parts of the world, patients with ESRD frequently receive two haemodialysis sessions per week and it is not unusual for these patients to present for renal transplantation with $\mathrm{Hb} \leq 11 \mathrm{~g} / \mathrm{dl}[8]$.

Delayed graft function (DGF) is an important complication of kidney transplantation and has detrimental effects on the early postoperative period as well as the long term outcome of the transplant. It is hypothesized that haemodialysis patients with anaemia have a higher risk of DGF post-transplantation compared to non-anaemic patients
[8]. It is thought that higher blood Hb level may have a protective effect against ischemia -reperfusion injury to the graft [8].

Pre-operative anaemia is known to be associated with considerable morbidity and mortality both in cardiac and non-cardiac surgery [9]. Compared with patients with normal preoperative $\mathrm{Hb}$, anaemic patients have an increased risk of myocardial infarction, infectious complications, prolonged hospitalization and a greater likelihood of allogenic red cell transfusion [9-11], with its associated risks and complications.

In our limited-resource set up, patients frequently present for transplantation with moderate and severe anaemia and are unable to receive ESAs or iron therapy. Hence, the aims of this study were to

${ }^{\star}$ Correspondence to: Ihab A. M. Ahmed, FRCS; MD; FRCS (Gen); CCT. Consultant Surgeon, Renal Transplant Unit, Sharg El-Neel Hospital, Khartoum, Sudan, Tel: (+)1-44-1388455180, (+)1-44-1388455054; E-mail: ihabahmed@doctors.org.uk

Key words: anaemia, kidney transplantation, cardiovascular, delayed graft function

Received: July 30, 2018; Accepted: August 09, 2018; Published: August 13, 2018 
assess the frequency of pre-transplant anaemia in a cohort of Sudanese renal transplant patients and to assess the association of anaemia with post-operative cardiovascular events, DGF and frequency of allogenic blood transfusion (ABT).

\section{Methods}

All patients who underwent living-related renal transplantation at Sharg El-Neel hospital during the period 1/1/2012 till 31/12/2012 and satisfied the set inclusion and exclusion criteria, were included in this study. Inclusion criteria included those patients who were $\geq 18$ years of age at the time of transplantation, patients with $\mathrm{Hb}$ level $\geq 7 \mathrm{~g} / \mathrm{dl}$ (the cut-off $\mathrm{Hb}$ level for accepting patients for transplantation in our centre) and those undergoing their first kidney transplantation.

Anaemia was defined according to the WHO classification of anaemia [12]. A patient is considered to have moderate anaemia if the $\mathrm{Hb}$ level is $8.0-10.9 \mathrm{~g} / \mathrm{dl}$ or severe anaemia if the $\mathrm{Hb}$ level is $<8.0 \mathrm{~g} /$ dl. However, due to the small sample size, patients were categorized as either anaemic if the $\mathrm{Hb}$ level was $\leq 10.9 \mathrm{~g} / \mathrm{dl}$ or as normal $\mathrm{Hb}$ if the level was $\geq 11 \mathrm{~g} / \mathrm{dl}$.

Due to the lack of a universal definition, DGF was defined in this study as the need for dialysis during the first seven days posttransplantation $[13,14]$.

Perioperative cardiac event was defined as the occurrence of symptoms compatible with acute myocardial ischemia, arrhythmia or congestive heart failure within 30 days post-transplantation. Symptoms compatible with acute myocardial ischemia included myocardial infarction (ST-segment elevated or non ST-segment elevated) or unstable angina. Diagnosis of myocardial infarction (MI) was made based on the clinical picture, recent ECG changes and elevation of the serum biomarkers, specifically Troponin $\mathrm{T}$, analysed at different time intervals. Diagnosis of unstable angina was made based on clinical picture and recent ECG changes [15].

In our center, as part of the assessment of the potential renal transplant recipients, $\mathrm{Hb}$ level was checked during the initial assessment and at admission for the operation. Generally, the cut-off $\mathrm{Hb}$ level for accepting patients for transplantation in our center was $7 \mathrm{~g} / \mathrm{dl}$, however, some exceptions were made on case by case basis. Pre-transplant assessment included a detailed cardiac history and clinical examination to detect any significant cardiac conditions including Acute Coronary Syndrome (ACS), heart failure, arrhythmias and valvular disease. Assessment for the functional class was also made (ability to climb two flights of stairs) [16]. Baseline ECG and echocardiogram were done for all cases. Any patient who showed features of cardiac compromise from history, clinical examination or investigations was referred to the cardiology service for further assessment and optimization.

Our immunosuppression protocol consisted of triple therapy. Tacrolimus was started 2 days pre-operatively at a dose of $0.15 \mathrm{mg} /$ $\mathrm{kg}$ body weight/day given in 2 divided doses and continued postoperatively, with the dose adjusted to keep the trough level at 10-15 $\mathrm{ng} / \mathrm{ml}$. Methylprednisolone was given intra-operatively at a dose of 500 $\mathrm{mg}$ before release of clamps and continued for 2 days post-operatively at a dose of $250 \mathrm{mg} /$ day. Oral prednisolone was started at the third postoperative day at a dose of $20 \mathrm{mg} /$ day. Azathioprine was started at the first post-operative day at a dose of $5 \mathrm{mg} / \mathrm{kg} /$ day. Tapering of immunosuppression was started six weeks post-operatively. Induction therapy was not used during the study due to the financial limitations, although it was introduced later.
Post-operatively, kidney function was monitored by measuring hourly urine output, daily measurement of serum urea, creatinine and electrolytes level and calculating creatinine clearance using Cock-Croft Gault formula. Laboratory assessment of full blood count was carried out on daily basis till the time of discharge, usually within 5 to 7 days post-operatively. Decision to give blood transfusion was made jointly between the surgeon and anaesthetist intra-operatively, if it was felt that there was excessive bleeding. Post-operatively, decision to give blood transfusion was made jointly between the surgeon and nephrologist if it was felt that there was excessive output from the surgical drains or if the $\mathrm{Hb}$ level dropped to below $7 \mathrm{~g} / \mathrm{dl}$.

According to our protocol, ECG and cardiac enzymes were requested if the patient complained of any symptoms suggestive of a cardiac event. These were repeated after 12 hours or as deemed necessary.

The variables included in this study were age at time of transplantation, sex, history of blood transfusion before transplantation, $\mathrm{Hb}$ level immediately before transplantation, need for transfusion during the perioperative period and number of units transfused, occurrence of cardiovascular events and episodes of DGF.

Ethical approval was granted, from the hospital's medical directorate, before the commencement of the study.

\section{Statistical Analysis}

Statistical analysis was performed using JMP software version 12. Continuous and categorical variables were displayed as means \pm standard deviation (SD) and frequencies and percentages, respectively. Student's $t$-test was used to assess the differences between continuous variables. Differences between categorical variables were analyzed using Fisher's exact test. $P$ values $<0.05$ were considered to be statistically significant.

\section{Results}

Forty three patients, with ESRD and on haemodialysis, underwent living related kidney transplantation during the study period. One patient was excluded because he was undergoing his second kidney transplantation. The remaining 42 patients satisfied the inclusion and exclusion criteria and were suitable for analysis. None of these patients was undergoing a pre-emptive transplant. Table 1 displays the characteristics of the study group and the distribution of variables included in the study. The patients' age ranged from 19 to 55 year with a mean (SD) of 32.8 (9.5) years. Two thirds of the sample (66.7\%) were males. Twenty six patients $(62 \%)$ were anaemic at the time of transplantation.

Table 1. Renal transplant patient characteristics. "DGF: Delayed graft function

\begin{tabular}{|l|l|l|}
\hline Subject characteristics & \multicolumn{1}{|c|}{\begin{tabular}{l} 
Mean (SD) \\
\hline Age (years)
\end{tabular}} & \\
\hline \multirow{2}{*}{ Sex } & male & \\
\hline \multirow{2}{*}{ Pre-operative Hb } & female & $28(66.7)$ \\
\hline Pre-transplant blood & $\leq 10.9 \mathrm{~g} / \mathrm{dl}$ & $14(33.3)$ \\
\hline transfusion & $\geq 11.0 \mathrm{~g} / \mathrm{dl}$ & $26(61.9)$ \\
\hline \multirow{2}{*}{ DGF* } & Yes & $16(38.1)$ \\
\hline \multirow{2}{*}{ Acute rejection } & No & $12(28.6)$ \\
\hline & Yes & $30(71.4)$ \\
\hline & No & $5(11.9)$ \\
\hline & Yes & $37(88.1)$ \\
\hline & No & $9(21.4)$ \\
\hline
\end{tabular}


The mean Hb level for the whole group was $10.2 \mathrm{~g} / \mathrm{dl}$ (range: $6.1-14$ ). Six patients had a $\mathrm{Hb}$ level less than $8 \mathrm{~g} / \mathrm{dl}$ (severe anaemia according to the WHO classification). Two patient were operated on with a Hb level below the set threshold of $7.0 \mathrm{~g} / \mathrm{dl}$ as both patient were running out of access sites and so were offered transplantation in spite of the very low $\mathrm{Hb}$. It was noticeable that males had a higher pre-operative $\mathrm{Hb}$ level compared to females, although that did not reach statistical significance $(p=0.076$,). Twelve patients $(28.6 \%)$ gave a past history of transfusion at some stage before coming for transplantation. The mean (SD) $\mathrm{Hb}$ on discharge for the studied group was $9.0 \mathrm{~g} / \mathrm{dl}$ (2.08). The mean (SD) postoperative creatinine level was $1.40 \mathrm{mg} / \mathrm{dl}(0.66)$.

There was neither perioperative mortality nor graft loss in the studied group. None of the patients included in the study developed any acute cardiovascular event during the perioperative period.

Of the 42 patients studied, five patients (12\%) developed DGF. Two of these patients were haemodialysed in the immediate post-operative period due to high serum potassium following intra-operative blood transfusion. Of these five patients with DGF, 4 patients were anaemic pre-operatively and one patient had normal $\mathrm{Hb}$ level. Table 2 summarizes the association of the examined parameters with pretransplant anaemia There was no statistically significant association between pre-operative anaemia and $\operatorname{DGF}(p=0.38$,). Also, there was no association between pre-operative $\mathrm{Hb}$ level and DGF ( $p=0.9$;).

Eleven patients $(25.6 \%)$ received blood transfusion during the perioperative period. The mean number of units (SD) transfused was 2.72 units (1.48). One patient needed ten units of blood due to excessive intra-operative bleeding. Eight of the patients who needed blood transfusion were anaemic pre-operatively. There was no significant association between pre-operative anaemia and the need for transfusion $(p=0.48)$. Three patients who received blood transfusion developed acute rejection. There was no statistically significant association between blood transfusion and episodes of acute rejection $(p=0.1$,$) .$

\section{Discussion}

Anaemia is a common complication of chronic kidney disease, the pathophysiology of which is related to reduced erythropoietin production, iron and vitamin deficiency, reduced erythrocytes life span, chronic inflammation and uraemic milieu [17-19]. Anaemia in CKD significantly increases the risks of cardiovascular morbidity and mortality as well as risk of stroke [20-22]. The prevalence of anaemia in CKD patients varies widely in different parts of the world, ranging from $47.8 \%$ to $75.8 \%$, depending on the stage of CKD [23]. Guidelines recommend routine assessment of anaemia in CKD patients and that ESAs and Iron therapy should be initiated if the $\mathrm{Hb}$ level falls to $<11.0$ $\mathrm{g} / \mathrm{dl}$. This treatment however, may not be available or affordable in certain parts of the world.

Table 2. Association of the parameters tested with pre-transplant anaemia. "DGF: Delayed graft function

\begin{tabular}{|c|c|c|}
\hline Parameters tested & $\begin{array}{l}\text { Association with pre- } \\
\text { transplant anaemia }\end{array}$ & P-value \\
\hline Sex & Mean $\mathrm{Hb}(\mathrm{SD})$ & \multirow{3}{*}{0.076} \\
\hline Male & $10.66 \mathrm{mg} / \mathrm{dl}(1.95)$ & \\
\hline Female & $9.47 \mathrm{mg} / \mathrm{dl}(2.1)$ & \\
\hline \multicolumn{2}{|l|}{$\mathrm{DGF}^{*}(\mathrm{n}=5)$} & \multirow{3}{*}{0.38} \\
\hline Anaemic & 4 & \\
\hline Normal & 1 & \\
\hline \multicolumn{2}{|c|}{ Patients requiring transfusion $(n=11)$} & \multirow{3}{*}{0.48} \\
\hline Anaemic & 8 & \\
\hline normal $\mathrm{Hb}$ & 3 & \\
\hline
\end{tabular}

The prevalence of anaemia in this study of ESRD patients presenting for transplantation was $62 \%$. However, this figure is not a true reflection of the prevalence of anaemia in our Sudanese ESRD population as patients with $\mathrm{Hb}<7 \mathrm{~g} / \mathrm{dl}$, the cut-off $\mathrm{Hb}$ level for patients to be offered transplantation, were excluded. The number of the patients excluded because of low $\mathrm{Hb}$ was not censored.

In spite of the low and sometimes very low Hb levels in our studied population, there was no acute cardiovascular events. This may be attributed to the fact that most of the patients belonged to young age group

Secondly, these patients were carefully evaluated pre-transplantation from cardiological point, as patients with pre-existing cardiac disease are at significantly increased risk for developing peri-operative cardiac complications after a renal transplant [24]. Patients with any suspected cardiac abnormality were referred to the cardiology services for further assessment. Hence this was a selected group of patients.

Five patients (12\%) developed DGF requiring haemodialysis. Of these five, two patients were dialysed immediately post-operatively due to high serum potassium, as these patients needed transfusion intra-operatively. We could not find statistically significant correlation between pre-operative anaemia or Hb level and DGF. This result is contrary to the previous reports that patients who were anaemic before transplantation have a higher risk of DGF [9].

This is the first study to report the prevalence of pre-transplant anaemia in Sudanese renal transplant population and its association with adverse cardiac events and DGF. To the best of our knowledge, there are no similar reports from sub-saharan Africa. There are, however, some limitations to this study. The main limitation is the small sample size which may have resulted in type II error. There are plans to reproduce this study with a larger sample size to be recruited from our center as well as other local centers. The other drawback is that most of the patients in this study group belonged to young age groups. It must be stressed that in our practice, patients are not denied transplantation because of old age (there was no upper age limit included in our protocol). Another limitation is that this was a retrospective study and thus causality cannot be determined. Future studies using prospective cohort design may provide greater control for bias and confounding factors.

In conclusion, offering renal transplantation to moderately anaemic patients was neither associated with adverse cardiac events nor with DGF. Patients should be carefully selected to ensure a favorable outcome. Further investigation with larger samples is required to determine the safety of this practice.

\section{References}

1. Bright $\mathrm{R}$ (1836) Cases and observations, illustrative of renal disease accompanied with the secretion of albuminous urine. In: Guy's hospital reports 1: 338-379.

2. Hsu CY (2002) Epidemiology of anemia associated with chronic renal insufficiency. Curr Opin Nephrol Hypertens 11: 337-341. [Crossref]

3. Hsu CY, McCulloch CE, Curhan GC (2002) Epidemiology of anemia associated with chronic renal insufficiency among adults in the United States: results from the Third National Health and Nutrition Examination Survey. J Am Soc Nephrol 13: 504.

4. Astor BC, Muntner P, Levin A (2002) Association of kidney function with anemia the Third National Health and Nutrition Examination Survey (1988-1994). Arch Intern Med 162: 1401 .

5. KDIGO (2013) 2012 Clinical Practice Guideline for the Evaluation and Management of Chronic Kidney Disease. Kidney Int Suppl 3: 1. 
6. Levin NW, Lazarus JM, Nissenson AR (1993) National Cooperative rHu Erythropoietin Study in patients with chronic renal failure--an interim report. The National Cooperative rHu Erythropoietin Study Group. Am J Kidney Dis 22: 3 .

7. Maïz HB, Abderrahim E, Zouaghi K (2002) Anemia and end-stage renal disease in the developing world. Artif Organs 26: 760-764. [Crossref]

8. Elhafiz M, Imam ME, Omran O, Gabar AA, Miskeen E (2009) Hemodialysis, Plea of Availability versus of Adequacy Gezira Experience, Sudan JMS 4: 7-10.

9. Molnar MZ, Kovesdy CP, Rosivall L, Bunnapradist S, Hoshino J, et al. (2012) Associations of pre-transplant anemia management with post-transplant delayed graft function in kidney transplant recipients. Clin Transplant 26: 782-791.

10. Fowler AJ, Ahmad T, Phull MK, Allard S, Gillies MA, et al. (2015) Meta-analysis of the association between preoperative anaemia and mortality after surgery. Br J Surg 102: $1314-1324$

11. Shander A, Van Aken H, Colomina MJ, Gombotz H, Hofmann A, et al. (2012) Patient blood management in Europe. Br J Anaesth 109: 55-68. [Crossref]

12. World Health Organization. Nutritional anaemias: Report of a WHO scientific group. Geneva, Switzerland: World Health Organization; 1968.

13. Siedlecki A, Irish W, Brennan DC (2011) Delayed graft function in the kidney transplant. Am J Transplant 11: 2279-2296. [Crossref]

14. Yarlagadda SG, Coca SG, Garg AX, Doshi M, Poggio E, et al. (2008) Marked variation in the definition and diagnosis of delayed graft function: a systematic review. Nephrol Dial Transplant 23: 2995-3003. [Crossref]
15. Kumar A, Cannon CP (2009) Acute coronary syndromes: diagnosis and management, part I. Mayo Clin Proc 84: 917-938. [Crossref]

16. Hlatky MA, Boineau RE, HigginbothamMB (1989) A brief self-administered questionnaire to determine functional capacity (The Duke activity status index). $\mathrm{Am}$ J Cardio 64: 651-654.

17. Erslev AJ, Besarab A (1995) The rate and control of baseline red cell production in hematologically stable patients with uremia. J Lab Clin Med 126: 283-286. [Crossref]

18. Eschbach JW (1989) The anemia of chronic renal failure: pathophysiology and the effects of recombinant erythropoietin. Kidney Int 35: 134-148.

19. Eschbach JW, Detter JC, Adamson JW (1980) Physiologic studies in normal and uremic sheep. II. Changes in erythropoiesis and oxygen transport. Kidney Int 18: 732 745. [Crossref]

20. Sarnak MJ, Levey AS (2000) Cardiovascular disease and chronic renal disease: a new paradigm. Am J Kidney Dis 35: S117-S131. [Crossref]

21. Wali RK, Henrich WL (2005) Chronic kidney disease: a risk factor for cardiovascular disease. Cardiol Clin 23: 343-362. [Crossref]

22. Keith DS, Nichols GA, Gullion CM, Brown JB, Smith DH (2004) Longitudinal followup and outcomes among a population with chronic kidney disease in a large managed care organization. Arch Intern Med 164: 659-663. [Crossref]

23. Salman, Muhammad (2016) Prevalence and management of anemia in pre-dialysis Malaysian patients: A hospital-based study. Rev Assoc Med Bras 62: 742-747.

24. Humar A, Kerr SR, Rancharan T (2001) Perioperative cardiac morbidity in kidney transplant recipients: incidence and risk factors. Clin Transplantation 15: 154-158.

Copyright: $\left({ }^{2} 2018\right.$ Ahmed IAM. This is an open-access article distributed under the terms of the Creative Commons Attribution License, which permits unrestricted use, distribution, and reproduction in any medium, provided the original author and source are credited. 